\title{
TÜRK BANKACILIK SEKTÖRÜNÜN KIRILGANLIĞI: AMPIRIKK BİR ÇALIŞMA
}

\author{
Ömer Faruk BÖLÜKBAŞI $\quad$ Emre ÜRKMEZ ${ }^{2}$ Osman KARAMUSTAFA ${ }^{3}$
}

Öz

Bu çalışma, Türkiye'de Bankacılık Kırılganlık Endeksi (BFI) ve ekonomik aktivite arasındaki ilişkiyi analiz etmeyi amaçlamaktadır. 2005-2016 dönemleri için aylık veriler kullanılııştır. Bankacılık kırılganlık endeksi takipteki alacaklar, sermaye yeterliliği oranı ve dönem net kar veya zararı serilerinden oluşmaktadır. Ekonomik aktiviteyi temsili olarak sanayi üretim endeksi büyüme oranı (IPI) kullanılmıştır. Öncelikle, finansal rasyoları aynı birimde tanımlamak amacıyla standardize edilmiş ve temel bileşenler analizi kullanılarak BFI oluşturulmuştur. Daha sonra, BFI ve IPI değişkenleri arasındaki nedenselliğin varlığını test etmek için Granger nedensellik analizi uygulanmıştır. Son olarak, değişkenler arasındaki dinamik ilişkiyi görebilmek için vektör otoregresif (VAR) modeli tahmin edilmiştir. Tahmin Sonuçlarına göre, BFI'nın ekonomik aktivite üzerinde önemli bir etkisi olmadığı ancak ekonomik aktivitenin BFI üzerinde etkili olduğu ortaya çıkarılmıştır. Granger nedensellik ve VAR analizi sonuçları birbirleri ile uyumlu olup bu bulguyu destekler nitelikte sonuçlar vermiştir.

Anahtar Kelimeler: Türk Bankacılık Sektörü, Bankacılık Kırılganlık Endeksi, VAR Analizi

JEL SInıflandırması: C32, C38, G01, G21

\section{TURKISH BANKING SECTOR FRAGILITY: AN EMPIRICAL STUDY}

\begin{abstract}
This study aims to analyze the relationship between the banking fragility index (BFI) and economic activity in Turkey. We use the monthly data for the period of 2005-2016. The BFI is composed of non-performing loans, capital adequacy ratio and net profit or lost for the period. Industrial production index growth rate (IPI) is used as a proxy for economic activity. Firstly, the financial ratios have been standardized to define in the same unit and the BFI is constituted by using the principal component analysis. Afterwards, Granger causality analysis conducted to test the existence of causality between the BFI and the IPI. Lastly, vector autoregression (VAR) model is employed to see the dynamic relationship between the BFI and the IPI variables. According to the results, the BFI has not significant influence on the IPI. However, the IPI impacts on the BFI. Granger causality and VAR analysis results are compatible with each other.
\end{abstract}

Keywords: Turkish Banking Sector, Banking Fragility Index, VAR Analysis

JEL Classification: C32, C38, G01, G21

\footnotetext{
${ }^{1}$ Arş.Gör., Ekonometri Bölümü, Recep Tayyip Erdoğan Üniversitesi, omer.bolukbasi@erdogan.edu.tr

${ }^{2}$ Arş.Gör., Ekonometri Bölümü, Recep Tayyip Erdoğan Üniversitesi, emre.urkmez@erdogan.edu.tr

${ }^{3}$ Prof. Dr., İşletme Bölümü, Recep Tayyip Erdoğan Üniversitesi, okaramustafa@erdogan.edu.tr
} 


\section{Giriş}

Ülke ekonomilerinde finansal sistemin güçlü yapısı, istikrarlı işleyişi ve reel ekonomi ile olan efektif etkileşimi küresel çapta meydana gelen krizlerin ülke ekonomisi üzerindeki kaçınılmaz etkilerini en aza indirmek için günümüz küresel dünyasında oldukça önem kazanmıştır. Küresel ölçekte etki gösteren 2008 finansal krizinin de etkisi ile ekonomik aktivite ile finansal piyasalarda gerçekleşen kırılganlık arasındaki ilişkilerin analizi araştırmacılar tarafından her geçen gün daha fazla ilgi görmektedir. Ekonomik karar birimleri bakımında da bu ilişkilerin tespiti doğru politikaların zamanında uygulanabilmesi açısından önem arz etmektedir. Literatürde, finans piyasasının işleyişinin genel durumunu temsil eden finansal stres endeksi ile reel ekonomi arasındaki ilişkileri inceleyen ve bu sayede kriz dönemleri öncesi ve sonrası da olası etkileşimleri hakkında bilgi sunan çalışmalar geniş bir yer tutmaya başlamıştır.

Bankacılık sektörü Türkiye finans sisteminin en önemli parçasıdır. Bankaların Türkiye'de faaliyet gösteren finansal kuruluşların toplam aktif büyüklükler içindeki payı \%86 düzeyindedir (TBB faaliyet raporu, 2015:19). Bankacılık sektörünün finansal piyasalarda bu denli bir baskınlığa sahip olması sağlam bir yapısı olan ve etkin işleyen bankacılık sisteminin finansal istikrarı sağlaması kadar reel sektörün küresel şoklardan olumsuz etkilenmemesi veya darboğaza düşülmemesi açısından da önemlidir. Bankacılık sektörünün finansal sektör içerisindeki önemi ve sahip olduğu temelde mevduat toplama ve kredi dağıtma fonksiyonları (Yağcılar, 2011:14) ile ekonomik sistemin işleyiş̧ini etkilemekte ve ekonomik sistemin istikrarı ve düzeni açısından önemli bir görev üstlenmektedir. Bankacılık sektöründeki gelişmeler ekonomik aktiviteyi olumlu veya olumsuz etkileyeceği gibi bankacılık sektörü ile reel ekonomi arasındaki etkileşim nedeni ile iktisadi değişimlerden de bankacılık sektörü etkilenecektir. Ekonomik aktivitede gerçekleşen olumsuzluklar bankacılık sektörünün etkinliğini azaltıp ekonomik sistemin düzeni açısından gerekli olan işlevlerini yerine getirmekte aksaklıklara yol açacaktır.

Bankacılık sektörünün genel görünümünü ile ilgili özet bilgiler ile beraber bazı temel oranlar Tablo 1'de sunulmuştur.

Tablo 1: Bankacılık Sektörü Genel Görünümü (2005-2016)

\begin{tabular}{|c|c|c|c|c|c|c|c|}
\hline $\begin{array}{l}\text { Yilla } \\
r\end{array}$ & $\begin{array}{c}\text { Aktif/GSY } \\
\text { H }\end{array}$ & $\begin{array}{c}\text { Mevduat/GSY } \\
\text { H }\end{array}$ & $\begin{array}{c}\text { Kredi/GSY } \\
\text { H }\end{array}$ & $\begin{array}{c}\text { Kredi/Akti } \\
\mathbf{f}\end{array}$ & $\begin{array}{c}\text { Kredi/Mevdua } \\
\text { t }\end{array}$ & $\begin{array}{c}\text { Bank } \\
\text { a } \\
\text { Şube } \\
\text { Sayısı }\end{array}$ & $\begin{array}{c}\text { Banka } \\
\text { Çalışan } \\
\text { Sayısı }\end{array}$ \\
\hline 2005 & 61.2 & 39.1 & 23.6 & 36.5 & 63.78 & 6400 & $\begin{array}{c}13577 \\
5\end{array}$ \\
\hline 2006 & 63.9 & 41.2 & 28.8 & 44.3 & 75.13 & 6967 & $\begin{array}{c}14470 \\
6\end{array}$ \\
\hline 2007 & 65.7 & 41.8 & 32.9 & 47.2 & 78.26 & 7682 & $\begin{array}{c}15802 \\
5\end{array}$ \\
\hline 2008 & 74.3 & 47.7 & 38.6 & 52.2 & 86.81 & 8782 & $\begin{array}{c}17775 \\
8\end{array}$ \\
\hline 2009 & 79.9 & 50.8 & 38.1 & 48 & 81.20 & 9328 & $\begin{array}{c}18136 \\
2\end{array}$ \\
\hline 2010 & 87 & 53 & 43.9 & 50.7 & 84.22 & 9726 & $\begin{array}{c}18839 \\
2\end{array}$ \\
\hline 2011 & 87 & 50.1 & 47.6 & 54.1 & 97.13 & 10342 & $\begin{array}{c}19428 \\
5\end{array}$ \\
\hline 2012 & 87 & 49.1 & 49 & 57.8 & 104.79 & 10698 & $\begin{array}{c}19764 \\
3\end{array}$ \\
\hline 2013 & 96 & 52.1 & 56.1 & 60.5 & 112.00 & 11485 & $\begin{array}{c}20879 \\
0\end{array}$ \\
\hline 2014 & 98 & 51.7 & 59.2 & 61.4 & 117.22 & 12072 & $\begin{array}{c}21505 \\
0\end{array}$ \\
\hline
\end{tabular}




\begin{tabular}{cccccccc}
\hline 2015 & 101 & 53.5 & 62.4 & 62.7 & 120.95 & 12207 & 21732 \\
2016 & 105 & 56.5 & 66.3 & 63.3 & 123.77 & 11849 & 21164 \\
7
\end{tabular}

Not: Veriler Türkiye Bankalar Birliği (TBB) ve Bankacılık Düzenleme ve Denetleme Kurumu (BDDK) veri tabanından temin edilmiştir.

Türk bankacılık sektörüne ait Tablo 1'de verilen temel göstergeler incelendiğinde aktif toplamının gayri safi yurtiçi hasılaya oranın 2005 yılından 2016 yılına kadar gelinen süreç içerisinde sürekli olarak yükseldiği 2015 yılı itibari ile de bankacılık sektörü aktif toplamının gayri safi yurtiçi hasıladan fazla olduğu gözlemlenmiştir. Mevduatların gayri safi yurtiçi hasılaya oranı yıllar itibari ile incelendiğinde 2016 yılında en yüksek seviyeye ulaştığı görülmektedir. Kredilerin gayri safi yurtiçi hasılaya oranı 2009 yılında 2008 yılına göre az da olsa gerileme olmuş ancak 2010 yılı itibari ile her yıl bu oranda artış gerçekleşmiştir. Kredilerin toplam aktifler içindeki payı da kredilerin gayri safi yurtiçi hasılaya oranına benzer şekilde 2009 yılında 2008 yılına göre azalma olmuş ve 2010 yılı itibari ile artarak 2016 yılında en yüksek seviyesine ulaşmıştır. Kredilerin mevduatlara oranı incelendiğinde 2009 yılındaki düşüş haricinde bu oranda yıllar itibari ile artış yaşanmıştır. Kredilerin mevduatlara oranına bakıldığında 2012 yılında başlamak üzere bankacılık sektöründe mevduat dışı kaynaklarında kredilere aktarıldığı söylenebilir. Banka şube sayısı ve çalışan sayısı incelendiğinde 2016 yılında 2015 yılına göre az bir miktar azalma olmasına rağmen 2005 yılına göre şube ve çalışan sayısında ciddi bir artış olmuştur. Ayrıca küresel krizin etkilerinin gözlemlendiği yıllarda şube sayısı ve çalışan sayısında azalma bir yana artış gözlemlenmiştir.

Bu çalışmanın amacı bankacılık sektörü için kırılganlığı gösteren bir endeks oluşturup, bu endeks ile ekonomik aktivite arasındaki ilişkileri Türkiye ekonomisinin 2005-2016 dönemi için incelemektir. Çalışmanın giriş bölümünü takiben ikinci bölümde ilgili ampirik çalışmalar sunulmuş ve bulgular özetlenmiştir. Çalışmanın üçüncü bölümünde veri seti ve ekonometrik yöntem hakkında bilgi verilip tahmin sonucunda elde edilen bulgular yorumlanmıştır. Çalışmanın dördüncü bölümü olan son kısmında ise sonuç ve değerlendirme yer almaktadır.

\section{Literatür Özeti}

Çalışmanın bu bölümünde Türkiye ekonomisi için bankacılık kırılganlık endeksi, finansal stres endeksi ve ekonomik aktivite arasındaki ilişkileri inceleyen ampirik çalışmalar özetlenmiştir. Çalışmalardan elde edilen bulgular incelendiğinde genel olarak finansal ve bankacılık sektöründeki kırılganlıklardaki artışların ekonomik aktiviteyi olumsuz etkilediği görülmektedir.

Tunay (2009) çalışmasında, 1988-2007 döneminde Türkiye Bankacılık sektörü için rekabetin, banka sektörü yapısının, yabancı bankaların ve makroekonomik değişkenlerin kırılganlık üzerindeki etkilerini incelemiştir. Kırılganlık göstergesi olarak ödenmemiş kredilerin toplam kredilere oranını bağımlı değişken olarak analize dahil etmiştir. Panel sabit etkiler ve panel logit modellerini bankaların uzmanlık alanı ve mülkiyet yapılarına göre ayrımını göz önünde bulundurarak tahmin etmiştir. Çalışmadan elde ettiği bulgulara göre reel faiz oranı, enflasyon, büyüme ve döviz kuru değişkenlerindeki dengesizliklerin kırılganlığı artırdığını ileri sürmüştür.

Elekdağ ve Kanlı (2010), Türkiye için 1996-2009 dönemini kapsayan finansal stres endeksi oluşturdukları çalışmalarında endeks ile sanayi üretim endeksi arasındaki ilişkiyi VAR yöntemi ile analiz etmişlerdir. Oluşturdukları finansal stres endeksi döviz piyasası baskı endeksi, hisse senedi piyasasına ait risk ve belirsizlik değişkenleri ve bankacılık sektörü riskini ölçen beta değerinden meydana gelmiştir. Elde ettikleri tahmin sonuçlarına göre finansal stres endeksindeki artışın ekonomik aktiviteyi temsilen analizde bulunan sanayi üretim endeksinde daralmaya yol açtığını ortaya koymuşlardır. Çalışmadan elde etikleri diğer önemli bulgular ise Türkiye'de ekonomik aktivitenin söz konusu dönemde finansal şoklardan hızlı bir şekilde etkilenip toparlanma sürecinin de hızlı olduğu yönündedir. 
Çevik vd. (2013), Türkiye ekonomisi için finansal stres endeksi ile ekonomik aktivite arasındaki ilişkiyi analiz ettikleri çalışmaları 1997-2010 dönemini kapsamaktadır. Finansal stres endeksini bankacılık sektörü, hisse senedi piyasası, döviz kuru piyasası ve dış borç verilerinden temel bileşenler analizi yöntemi ile oluşturmuşlardır. Çalışmada ekonomik aktivite göstergeleri olarak sanayi üretim endeksi, dış ticaret ve yatırım makroekonomik değişkenlerini kullanmışlardır. Granger nedensellik analizi bulguları doğrultusunda finansal stres endeksindeki değişimlerin ekonomik aktiviteyi anlamlı bir şekilde etkilediği ancak ekonomik aktivitenin endeks üzerinde anlamlı bir etkisi olmadığı bulgusuna ulaşmışlardır. VAR analizinden elde ettikleri tahmin sonuçlarına göre finansal stres endeksindeki artışın ekonomik aktiviteyi azalttığı sonucuna ulaşmışlardır.

Demirel ve Karanfil (2015), Türkiye ekonomisi 2008-2014 dönemi için Kibritçioğlu (2003) ve Singh(2010) çalışmalarını referans alarak bankacılık kırılganlık endeksi oluşturmuşlardır. Endeksi etkilediğini düşündükleri makroekonomik değişkenlerin endeks üzerindeki etkilerini VAR ve Eş bütünleşme modelleri ile analiz etmişlerdir. Johansen koentegrasyon testi tahmin sonuçlarına sonuçlarına göre değişkenler arasında Eş bütünleşme ilişkisi olduğunu tespit etmişlerdir. Hata düzeltme modeli bulgularına göre enflasyon, mevduat faiz oranı, reel döviz kuru, dış ticaret şokları, JP Morgan EMBI+ ve cari açık değişkenlerinin endeks üzerinde pozitif etkileri, kredi faiz oranı ve FED faiz oranı değişkenlerinin endeks üzerindeki etkilerinin negatif olduğunu belirlemişlerdir. VAR analizi tahmin sonuçları doğrultusunda JP Morgan EMBI+ ve dış ticaret şoklarının endeks üzerinde kısa dönem pozitif, FED faiz oranın ise endeksi kısa dönem negatif etkilediğini ortaya koymuşlardır.

Aklan vd. (2015), finansal stres endeksi ile ekonomik aktivite arasındaki ilişkiyi inceledikleri çalışmalarında Türkiye ekonomisinin 2002-2014 dönemini analiz etmişlerdir. Finansal stres endeksini bankacılık sektörünü de kapsayacak şekilde hisse senedi, döviz piyasası ve kamu sektörünü de içeren değişkenlerden oluşturmuşlardır. Ekonomik aktiviteyi temsilen sanayi üretim endeksi büyümesi, dış ticaret hacmi, iç borç kullanım oranı değişkenleri analizlerde kullanmışlardır. Oluşturdukları finansal stres endeksi ile ekonomik aktivite arasındaki ilişkiyi Granger nedensellik ve VAR yöntemleri ile incelemişlerdir. Granger nedensellik tahmin sonuçlarına göre finansal stres endeksinden ekonomik aktiviteye doğru tek yönlü bir nedensellik ilişkisi tespit etmişlerdir. VAR analizinden elde ettikleri etki-tepki fonksiyonlarına göre finansal stres endeksindeki artışın ekonomik aktivite üzerinde olumsuz etkisi olduğu bulgusuna ulaşmışlardır.

Demirel vd. (2016), 2010-2015 dönemi Türkiye ekonomisi bankacılık sektörü için kırılganlık endeksi oluşturmuşlar ve söz konusu dönemde makroekonomik faktörlerin endeks üzerindeki etkilerini analiz etmişlerdir. Ekonometrik yöntem olarak Johansen Eş-bütünleşme ve hata düzeltme modellerini kullanarak olası kısa ve uzun dönem ilişkileri incelemişlerdir. Elde ettikleri bulgulara göre değişkenler Eş bütünleşiktir. Hata düzeltme modeli tahmin sonuçlarına göre kısa dönemde reel döviz kuru, enflasyon, takipteki krediler, faiz oranı, volatilite endeksi ve FED politikasındaki değişimlerdeki artışın kırılganlığı artırdığı, sanayi üretim endeksindeki artışın ise kırılganlığı azaltacağı yönündedir.

Varlık ve Varlık (2016), Türkiye ekonomisinin 2004-2015 döneminin kapsayan çalışmalarında bankacılık sektörü için sağlamlık endeksi oluşturmuşlar ve VAR yöntemi ile risk algısının endeks üzerindeki etkilerini ortaya koymuşlardır. Sağlamlık Endeksini faktör analizi yöntemini kullanarak oluşturmuşlardır. Faktör analizi sonuçları doğrultusunda endeksi, sermaye yeterliliği, karlılık, kredi riski, faiz ve kur riski olmak üzere dört bileşenden oluşturmuşlardır. VAR analizi sonuçlarına göre küresel risk iştahı, ülke risk primi, küresel risk primi ve faiz oranındaki artışlar karşısında endeksin olumsuz etkilendiğini, borsa performansındaki yükselişten olumlu etkilendiğini tespit etmişlerdir.

Kaya ve Kılınç (2017), Türkiye'de 2002-2015 dönemi için finansal stres endeksi ile ekonomik aktivite arasındaki ilişkiyi inceledikleri çalışmada Granger nedensellik ve VAR yöntemlerini kullanmışlardır. Finansal stres endeksini bankacılık, döviz, hisse senedi piyasaları ve kamu sektörü için baskı endeksleri oluşturduktan sonra söz konusu endekslere eşit ağırlık vermek sureti ile oluşturmuşlardır. Oluşturdukları finansal stres endeksinin söz konusu dönemde Türkiye'de yaşanan 
finansal gelişmeleri temsil kabiliyetinin iyi olduğunu ileri sürmüşlerdir. Çalışmadan elde ettikleri bulgulara göre finansal sıkıntı endeksinin ekonomik aktiviteyi istatistiksel olarak anlamlı etkilediği sonucuna ulaşmışlardır.

\section{Veri Seti ve Yöntem}

\subsection{Veri Seti}

Bu çalışmada 2005-2016 dönemleri arasında aylık veriler kullanılarak Türkiye'nin bankacılık sektörünün kırılganlığı analiz edilmiştir. Bu amaçla bankacılık kırılganlık endeksini (banking fragility index, BFI) oluşturmak için takipteki alacakların toplam nakdi kredilere oranı (TA), sermaye yeterliliği standardı oranı (SY) ve dönem net karı veya zararı'nın ortalama özkaynaklara oranı (DNK) değişkenlerinden oluşan üç temel rasyo kullanılmıştır. Bunun yanında BFI ile sanayi üretim endeksi (SUE) arasındaki dinamik ilişkinin analizi vektör otoregresif model (VAR) çerçevesinde ele alınmıştır. Çalışmada kullanılan finansal seriler Bankacılık Düzenleme ve Denetleme Kurumu (BDDK)'nin istatistik veri tabanından ve SUE serisi ise Türkiye Cumhuriyet Merkez Bankası EVDS'den temin edilmiştir.

\subsection{Ekonometrik Yöntem}

\subsubsection{Türkiye için Bankacılık Kırılganlık Endeksinin (BFI) Oluşturulması}

Bankacılık sektörü Türkiye finans sisteminin en önemli parçasıdır. Sağlam bir yapısı olan ve etkin işleyen bir bankacılık sistemi, küresel krizlere karşı ülke ekonomisini daha az kırılgan bir konuma getirir. Bankacılık sektöründe meydana gelen gelişmeler finansal açıdan olduğu kadar reel sektör için de büyük önem arz etmektedir. Bankacılık sektörünün kırılganlığını ölçen bankacılık kırılganlık endeksi oluşturulup seyrinin izlenmesi ve yüksek kırılganlık dönemlerinin tespiti ekonomik birimler ve karar alıcılılar tarafından önemlidir.

Bu çalışmada bankacılık kırılganlık endeksini oluşturacak bileşenlerin seçimini iki başlık altında toplayabiliriz: Birincisi, endekste yer alan değişkenlerin yayınlanma sıklığı. İkincisi, değişkenlerin ekonominin olası daralma dönemlerini yakalayabilmesidir. Çalışmada kullanılan finansal rasyoların tek bir endeks içerisinde ele alınabilmesi için aşağıdaki işlemler sırası ile uygulanmıştır. Öncelikle tüm finansal rasyoları aynı birimde tanımlamak amacıyla TA, SY ve DNK değişkenleri standardize edilmiştir. Yani her bir değişken ortalaması sıfır varyansı bir olacak şekilde yeniden düzenlenmiştir. Bu işlem (1) nolu Eşitlikte tanımlanmıştır:

$$
S T A=\frac{T A-\mu_{T A}}{\sigma_{T A}}, S S Y=\frac{S Y-\mu_{S Y}}{\sigma_{S Y}} \text { ve } S D N K=\frac{D N K-\mu_{D N K}}{\sigma_{D N K}}
$$

Daha sonra, standardize edilmiş değişkenlere temel bileşenler analizi yöntemi uygulanarak değişkenlerin endeks içindeki ağırlıkları hesaplanmıştır. Temel bileşenler yöntemine göre her bir seri için hesaplanan ağırlıklar Tablo 2'de sunulmuştur.

Tablo 2: Temel Bileşenler Analizi Yöntemi ile Hesaplanan Ağırlıklar

\begin{tabular}{cc}
\hline Değişkenler & Ağırlıklar \\
\hline STA & 0.959 \\
SSY & 0.952 \\
SDNK & 0.225 \\
\hline
\end{tabular}

Bankacılık kırılganlık endeksi temel bileşenler analizi yöntemine göre hesaplanan ağırlıklara göre oluşturulmuş ve bu işlem (2) nolu Eşitlikte tanımlanmıştır:

$$
B F I=S T A(0.959)+S S Y(0.952)+\operatorname{SDNK}(0.225)
$$


Oluşturulan bu endeks üç değişkendeki toplam değişimin \%62,5'ni açıklamaktadır. Son olarak da oluşturulan BFI standardize edilerek ortalaması sıfır ve varyansı bir olması sağlanmıştır. Bu aşamada endeksin pozitif değer alması kırılganlığın arttığına, negatif değer alması kırılganlığın azaldığına ve endeksin sıfır değeri alması ise kırılganlığın değişmediği yani sabit kaldığı şeklinde yorumlanacaktır. Bankacılık kırılganlık endeksi ile sanayi üretim endeksi büyüme oranı serileri Grafik 1'de gösterilmiştir.

Grafik 1: Bankacilık Kırılganlık Endeksi ve Sanayi Üretim Endeksi Büyüme Oranı

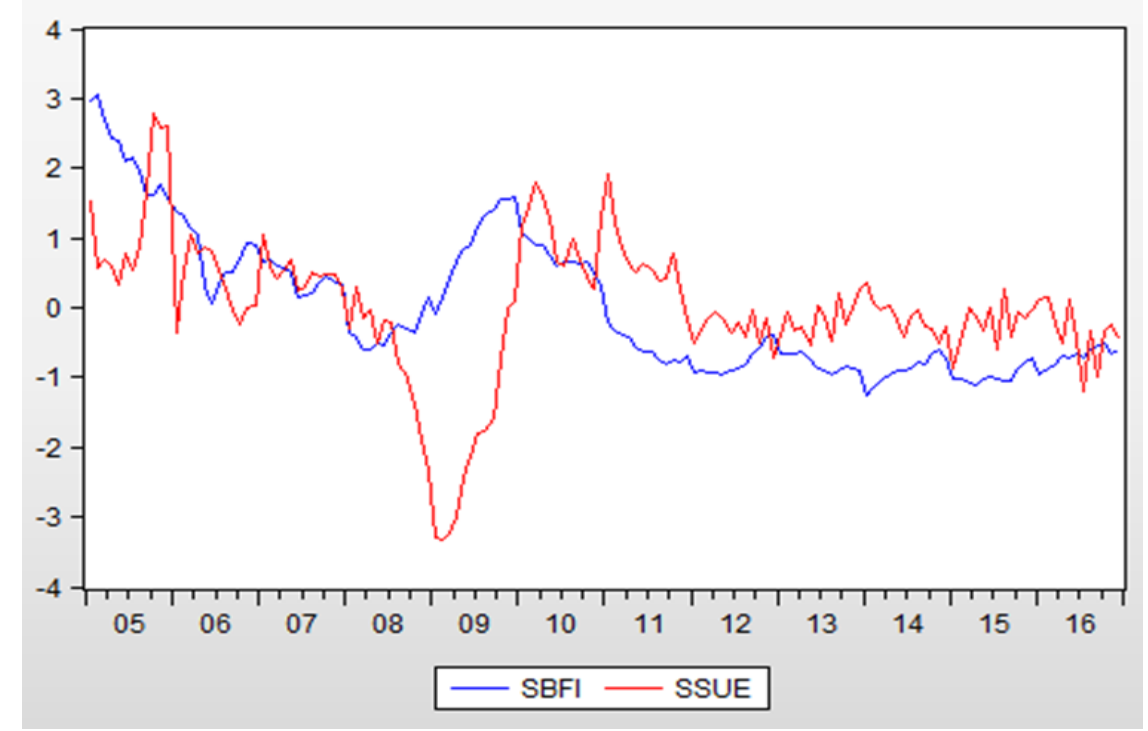

\section{Ampirik Bulgular}

Ekonometrik model tahminlerine geçmeden önce serilerin durağanlığını analiz etmek amacıyla Zivot-Andrews (ZA, 1992) birim kök testi yapılmış ve sonuçlar Tablo 3'de özetlenmiştir. Durağanlık analizi sonuçlarına göre, BFI değişkeni için her iki modele göre tablo kritik değeri test istatistiğinden daha negatif olduğundan sıfır hipotezi reddedilememiş, BFI değişkeninin fark durağan süreç (DSP) olduğu tespit edilmiştir. Bu nedenle serinin birinci farkı alınarak Genişletilmiş Dickey-Fuller (ADF, 1979) birim kök testi uygulanmıştır. ADF test istatistiği -9.05 hesaplanarak BFI serisinin fark durağan olduğu belirlenmiştir. Daha sonra SUE değişkeni için hem sabitteki hem de eğimdeki değişmeyi gösteren kukla değişkenler anlamlı olduğundan Model C tercih edilmiştir. Model C'e göre test istatistiği değeri tablo kritik değerinden daha negatif olduğundan sıfır hipotezi reddedilmiş, SUE değişkeninin trend durağan süreç (TSP) olduğu tespit edilmiştir. Bu nedenle ekonometrik model tahminlerinde BFI değişkeninin birinci farkıyla ve SUE değişkeninin ise trendden arındırılmış haliyle çalışılmıştır.

Tablo 3: Zivot-Andrews Birim Kök Testi Sonuçları

\begin{tabular}{|c|c|c|c|c|c|}
\hline \multirow{2}{*}{ Değişkenler } & \multirow{2}{*}{ Gecikme Uzunluğu } & \multirow{2}{*}{ Açıklama } & \multicolumn{2}{|c|}{ Alternatif Modeller } & \multirow[t]{2}{*}{ Süreç } \\
\hline & & & Model A & Model C & \\
\hline \multirow{6}{*}{$\mathrm{BFI}$} & & Test & & & \multirow{5}{*}{$\mathrm{DSP} /(1)$} \\
\hline & & İstatistiği & -3.9717 & -3.9076 & \\
\hline & $k=1$ & & & & \\
\hline & & TB & $2010 \mathrm{M} 12$ & $2010 \mathrm{M} 12$ & \\
\hline & & Test & & & \\
\hline & & İstatistiği & -4.5055 & -5.3905 & \multirow{3}{*}{ TSP } \\
\hline \multirow[t]{2}{*}{ SUE } & $k=0$ & & & & \\
\hline & & TB & $2009 M 10$ & $2009 \mathrm{M} 10$ & \\
\hline
\end{tabular}


Not: ZA testinde Model A sabit ve Model C ise sabit ve eğimin her ikisinde meydana gelen değişimi gösteren modellerdir. Tablo kritik değerleri \%5 anlam düzeyinde sırasıyla -4.80 ve -5.08 'dir. TB kırılma zamanı, DSP fark durağan süreci ve TSP ise trend durağan süreci ifade etmektedir.

Daha sonra sanayi üretim endeksi büyüme oranı ile bankacılık kırılganlık endeksi arasındaki ilişkinin yönünü belirlemek amacıyla Granger nedensellik testi yapılmış ve sonuçlar Tablo 4'de sunulmuştur.

Tablo 4: Granger Nedensellik Testi Sonuçları

\begin{tabular}{|c|c|c|c|c|}
\hline Sıfır Hipotezi $\left(\mathrm{H}_{0}\right)$ & F İstatistiği & $\begin{array}{l}\text { Kuyruk } \\
\text { Olasılığı }\end{array}$ & LM Testi & Karar \\
\hline $\begin{array}{l}\text { SUE, BFI'nin Granger nedeni } \\
\text { değildir. }\end{array}$ & $5.26953 *[2]$ & 0.0062 & $\begin{array}{c}2.0234 \\
(0.3636)\end{array}$ & RED \\
\hline $\begin{array}{l}\text { BFI, SUE'nin Granger nedeni } \\
\text { değildir. }\end{array}$ & $1.46643[2]$ & 0.2344 & $\begin{array}{c}2.9729 \\
(0.2262)\end{array}$ & KABUL \\
\hline
\end{tabular}

Not: * \%5 anlam düzeyinde anlamlı olduğunu göstermektedir. Gecikme uzunlukları 2 olarak belirlenmiştir.

Granger nedensellik testi sonuçlarına göre, \%5 anlam düzeyinde SUE'den BFI'ya doğru Granger nedensellik ilişkisi tespit edilirken, BFI'dan SUE'ne doğru Granger nedensellik ilişkisi tespit edilememiştir. Kısaca Türkiye'de SUE'den BFI'ya doğru tek yönlü Granger nedensellik ilişkisinin var olduğu belirlenmiştir.

Son olarak çalışmada, Türkiye'de bankacılık sektöründeki gelişimler ile ekonomik aktivite arasındaki ilişkinin daha iyi anlaşılması amacıyla vektör otoregresif model (VAR) oluşturulmuştur. Modelde, Türkiye için hesaplanmış olan BFI ile ekonomik büyümeyi temsilen sanayi üretim endeksi büyüme oranı (SUE) değişkenleri kullanılmıştır. Çalışmada VAR modelinin uygun gecikme uzunluğunu belirlemek amacıyla LR test istatistiği, Akaike (AIC) ve Schwarz (SC) bilgi kriterlerinden yararlanılmış ve optimal gecikme uzunluğu 1 olarak belirlenmiştir. $\operatorname{VAR}(1)$ modelinde otokorelasyon sorunu olup olmadığını incelemek amacıyla LM testinden faydalanılmıştır. Test sonucunda birinci veya daha yüksek mertebeden otokorelasyon olmadığı görülmüştür ${ }^{4}$. Daha sonra hata terimlerinin örneklem dönemi için varyansının sabit olup olmadığının test etmek amacıyla çarpım terimsiz White testi uygulanmış ve sabit varyans varsayımının geçerli olduğu sonucuna ulaşılmıştır ${ }^{5}$. Son olarak VAR(1) modelinin kararlı olup olmadığı grafiksel yöntemle analiz edilmiş ve karakteristik köklerin birim çember içinde yer aldığı görülmüştür. Bu nedenle modelin kararlı ve durağanlık koşullarını sağladığı sonucuna ulaşılmıştır.

VAR(1) modeli tahmin edildikten sonra yapılan etki-tepki fonksiyonu analizlerine ilişkin bulgular, Grafik 2'de gösterilmiştir. Buna göre (b) panelinde sanayi üretim endeksi büyüme oranına rassal şok verildiğinde bu şokun bankacılık kırılganlık endeksi üzerindeki etkisi ele alınmaktadır. Bulunan sonuçlar sanayi üretim endeksi büyüme şoklarının bankacılık kırılganlık endeksini azaltma eğiliminde olduğudur. Başka bir ifadeyle, sanayi üretim endeksi büyüme oranı ile bankacılık kırılganlık endeksi arasında ters yönlü bir ilişki olduğu söylenebilir. O halde sanayi üretim endeksi büyüme oranında meydana gelen 1 standart sapmalık pozitif şok karşısında, bankacılık kırılganlık endeksi on ikinci döneme kadar azalmakta, daha sonra ise giderek etkinin azaldığı görülmektedir.

Bu durumda sanayi üretim endeksi büyüme oranı artarsa bankacılık kırılganlık endeksi azalır veya sanayi üretim endeksi büyüme oranında küçülme yaşandığında bankacılık kırılganlık endeksi artar. (c) panelinde ise bankacılık kırılganlık endeksinin sanayi üretim endeksi büyüme oranına tepkisi sunulmuştur. Buna göre bankacılık kırılganlık endeksine rassal şok verildiğinde bu şokun sanayi üretim endeksi büyüme oranı üzerindeki etkisi ele alınmaktadır. Bulunan sonuçlar bankacılık kırılganlık endeksi şoklarının sanayi üretim endeksi büyüme oranını azda olsa arttırma eğiliminde

${ }^{4}$ VAR(1) modeli için hesaplanan LM(1) test istatistiği sonucu 2.3163 olarak bulunmuştur. LM test istatistiği sonucuna göre otokorelasyon olmadığı ifade edilen sıfır hipotezi reddedilememiştir.

${ }^{5}$ VAR(1) modeli için hesaplanan White test istatistiği sonucu 12.89 olarak hesaplanarak, sabit varyans varsayımını geçerli olduğu sıfır hipotezi reddedilememiştir. 
olduğudur. O halde bankacılık kırılganlık endeksinde meydana gelen 1 standart sapmalık pozitif şok karşısında, sanayi üretim endeksi büyüme oranı ikinci döneme kadar düşüş yönünde, ikinci dönemden sonra artış yönünde tepki verdiği görülmüştür.

\section{Grafik 2: Etki-Tepki Analizi Sonuçları}

Response to Cholesky One S.D. Innovations \pm 2 S.E.

(a) Response of BFI to BFI

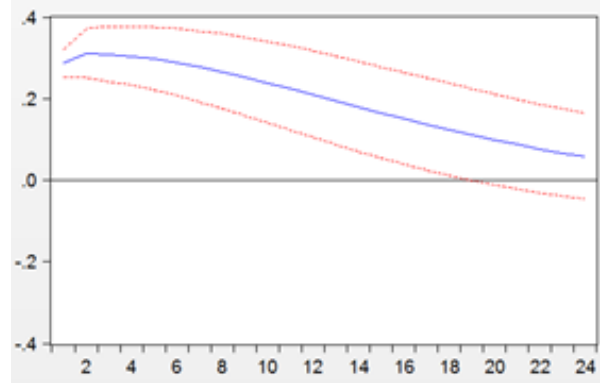

(c) Response of SUE to BFI

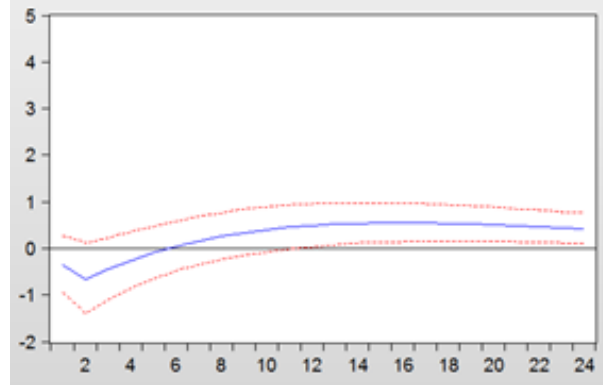

(b) Response of BFI to SUE

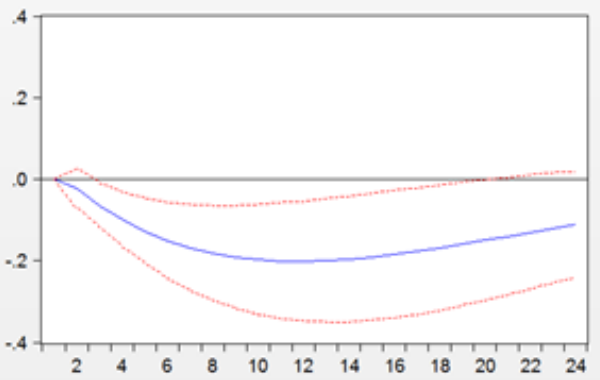

(d) Response of SUE to SUE

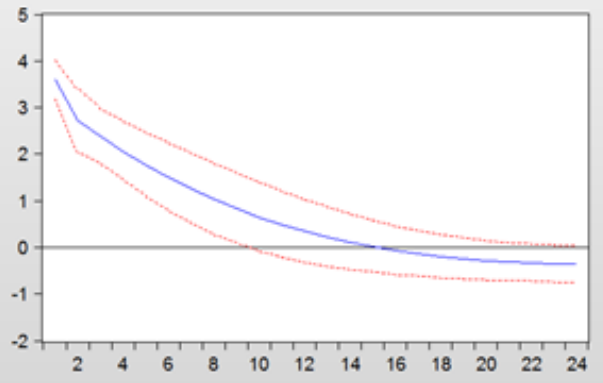

VAR(1) modeli için yapılan varyans ayrıştırma analizi sonuçları Tablo 5 ve Tablo 6'da sunulmuştur. Varyans ayrıştırma analizi bir değişkenin varyansında meydana gelen değişimin kendisi ve diğer değişkenler tarafından açıklanma yüzdelerini gösterir.

İlk olarak bankacılık kırılganlık endeksi serisi için varyans ayrıştırması sonuçları Tablo 5 'de verilmiştir. 2005-2016 dönemleri arasında bankacılık kırılganlık endeksinin öngörü hatasında meydana gelen değişimin ilk dönemde kendisini yüzde yüz açıklarken, altıncı dönemde \%90'ını ve on ikinci dönemde ise \%76'sını açıkladığı görülmektedir.

Tablo 5: Bankacılık Kırılganlık Endeksi Serisi için Varyans Ayrıştırması Sonuçları

\begin{tabular}{cccc}
\hline Dönem & Standart Hata & BFI & SUE \\
\hline 1 & 0.2866 & 100.00 & 0.00 \\
2 & 0.4225 & 99.69 & 0.30 \\
3 & 0.5267 & 98.28 & 1.71 \\
4 & 0.6160 & 96.14 & 3.85 \\
5 & 0.6957 & 93.60 & 6.39 \\
6 & 0.7679 & 90.90 & 9.09 \\
7 & 0.8337 & 88.19 & 11.80 \\
8 & 0.8937 & 85.57 & 14.42 \\
9 & 0.9481 & 83.09 & 16.90 \\
10 & 0.9974 & 80.79 & 19.20 \\
11 & 1.0417 & 78.67 & 21.32 \\
12 & 1.0813 & 76.74 & 23.25 \\
\hline
\end{tabular}

Daha sonra sanayi üretim endeksi büyüme oranı serisi için varyans ayrıştırması sonuçları Tablo 6'da sunulmuştur. Sanayi üretim endeksi büyüme oranının öngörü hatasında meydana gelen 
değişimin ilk dönemde kendisini yüzde yüz açıklarken, sonraki dönemlerde pek değişmediği görülmüştür.

Tablo 6: Sanayi Üretim Endeksi Serisi için Varyans Ayrıştırması Sonuçları

\begin{tabular}{cccc}
\hline Dönem & Standart Hata & BFI & SUE \\
\hline 1 & 3.6113 & 0.91 & 99.08 \\
2 & 4.5704 & 2.66 & 97.33 \\
3 & 5.1705 & 2.81 & 97.18 \\
4 & 5.5728 & 2.63 & 97.36 \\
5 & 5.8483 & 2.42 & 97.57 \\
6 & 6.0383 & 2.27 & 97.72 \\
7 & 6.1697 & 2.24 & 97.75 \\
8 & 6.2608 & 2.34 & 97.65 \\
9 & 6.3246 & 2.57 & 97.42 \\
10 & 6.3705 & 2.93 & 97.06 \\
11 & 6.4051 & 3.40 & 96.59 \\
\hline
\end{tabular}

\section{Sonuç}

Türkiye'de finans sisteminin en büyük parçası bankacılık sektörüdür. Bankacılık sektöründe meydana gelebilecek olası bir daralma bankacılık sektörünün büyüklüğü ve işlevleri göz önüne alındığında finansal istikrar açısından olduğu kadar reel ekonomi ile etkileşimi bakımından da önem arz etmektedir. Küresel krizlerin de etkisi ile reel ekonomi de ortaya çıkacak daralmalar karşııında bankacılık sektörünün kırılganlığı yükselebileceği gibi bankacılık sektöründe yaşanacak olumsuzlukların yatııım veya tüketim kanalları ile reel ekonomi üzerinde negatif etkileri olabilecektir.

Bu çalışmada öncelikle 2005-2016 dönemi için Türk bankacılık sektörünün kırılganlığını yansıtan bankacılık kırılganlık endeksi oluşturulmuş ve kırılganlığın seyri analiz edilen dönem itibari ile incelenmiştir. Bankacilık kırılganlık endeksi sektörün en önemli rasyolarından olan ve endeksin söz konusu dönem için Türkiye ekonomisinde yaşanan gelişmelere uyumlu olarak hareket etmesi dikkate alınarak takipteki alacakların toplam nakdi kredilere oranı, sermaye yeterliliği standardı oranı, dönem net karı veya zararının ortalama özkaynaklara oranları temel bileşenler analizi yöntemine göre ağılıklandırılarak oluşturulmuştur. Elde edilen bankacılık kırılganlık endeksi dönemler itibari ile incelendiğinde sanayi üretim endeksi ile zıt yönlü hareket ettiği tespit edilmiştir. Sanayi üretim endeksinin yükseldiği(azaldığı) dönemlerde bankacılık kırılganlık endeksinin azaldığı(yükseldiği) gözlemlenmiştir. 2008 yılında gerçekleşen küresel finansal krizin de etkisi ile reel ekonomide yaşanan daralma sonucu birkaç dönem gecikme ile birlikte bankacılık sektörü kırılganlığı yükselmiştir.

Çalışmada bankacılık kırılganlık endeksi oluşturulup 2005-2016 dönemi için zaman serisi seyri incelendikten sonra elde edilen bu endeks ile reel ekonomi arasındaki olası ilişkinin incelenmesi amacı ile Granger nedensellik ile VAR analizi yöntemleri kullanılmıştır. Granger nedensellik testi sonucuna göre Sanayi üretim endeksinin Bankacılık kırılganlık endeksinin granger nedeni olduğu ancak bankacılık kırılganlık endeksinin sanayi üretim endeksinin granger nedeni olmadığı tespit edilmiştir. Etki tepki analizi sonuçlarına göre BFI ile ekonomik aktivite arasında negatif yönlü ilişki olduğu belirlenmiş ve reel ekonomide yaşanana daralma sonucu BFI'nın yükseleceği ortaya çıkarılmıştır. Son olarak varyans ayrıştırması sonuçlarına göre, BFI'nın öngörü hatasında meydana gelen değişimin kendisi tarafından açıklanma oranının ilk altı aylık dönemde $\% 90,90$ olduğu ve ilerleyen dönemlerde azalarak 12. dönemde 76.74 olduğu tespit edilmiştir. SUE değişimlerin ise büyük ölçüde kendisi tarafından açıklandığı belirlenmiştir.

Tüm bulgular bir arada değerlendirildiğinde, BFI'nın ekonomik aktivite üzerinde önemli bir etkisi olmadığı ancak ekonomik aktivitenin $\mathrm{BFI}$ üzerinde etkili olduğu ortaya çıkarılmıştır. Granger nedensellik ve VAR analizi sonuçları birbirleri ile uyumlu olup bu bulguyu destekler nitelikte sonuçlar elde edilmiştir. Çalışmada bankacilık sektöründe yaşanan gelişmelerin reel ekonomi üzerinde etkisi olmayacağı belirlenmekle birlikte bu duruma neden olarak her ne kadar son yıllarda 
özel sektörün yatırımlarının teşvik edilip etkinliğinin artıııması amaçlanmasa da kamu sektörünün bankacılık kaynaklarından daha fazla yararlanması sonucu oluşan verimlilik kaybının olduğu ileri sürülebilir.

\section{Kaynakça}

Aklan, N. A., Çınar, M. ve Kanalıcı Akay, H. (2015). Financial Stress and Economic Activity Relationship In Turkey: Post-2002 Period. Yönetim ve Ekonomi: Celal Bayar Üniversitesi iktisadi ve Idari Bilimler Fakültesi Dergisi, 22(2), 567-580.

BDDK İnteraktif Bülten. (2017). Erişim Adresi http://ebulten.bddk.org.tr/ABMVC/tr.

BDDK, Türk Bankacılık Temel Göstergeleri. (2017). Erişim Adresi http://www.bddk.org.tr/WebSitesi/turkce/Raporlar/TBSGG/16208tbs_temel_gostergele r_raporu_haziran_2017.pdf.

Çevik, E. İ., Diboğlu, S. ve Kenç, T. (2013). Measuring Financial Stress in Turkey. Jornal of Policy Modeling, 35(2), 370-383.

Demirel, B. ve Karanfil, N. (2015). Bankacılık Sektöründe Banka Kırılganlık Endeksini Belirleyen Faktörler. EY international Konferance on Economics II 5-6 Kasım 2015, Ekonomik Yaklaşım, Ankara. Erişim Adresi http://ekonomikyaklasim.org/eyc2015/userfiles/downloads/_Paper\%2030.pdf.

Demirel, B., Barışık, S. ve Karanfil, N. (2016). Türk bankacılık Sektörü Kırılganlık Endeksini Belirleyen Faktörler. Bankacılar Dergisi, 99, 16-36.

Elekdağ, S. ve Kanlı, I. B. (2010). Finansal Stres ve İtisadi Faaliyet. TCMB Ekonomi Notları, 2010-6, 1-5.

Enders, W. (2010). Applied Econometric Time Series (3rd ed.). New Jersey: Wiley.

Göçmen Yağcılar, G. (2011). Türk Bankacılık Sektörünün Rekabet Yapısının Analizi. Ankara: Bankacılık Düzenleme ve Denetleme Kurumu.

Gujarati, D. N. ve Porter, D.C. (2010). Essentials of Econometrics (5th ed.). New York: McGrawHill/Irwin.

Kaya, E. Ve Kılınç, A. (2016). Türkiye için Finansal Sıkıntı Endeksinin Ölçümü ve Finansal Sıkıntı Endeksinin Reel Ekonomik Faaliyetler ile ilişkisi. Uluslararası Yönetim iktisat ve işletme Dergisi, 16(özel sayı), 402-413.

Sevüktekin, M. ve Çınar, M. (2014). Ekonometrik Zaman Serileri Analizi: Eviews Uygulamalı (4. Baskı). Bursa: Dora Yayıncılık.

TBB, Türkiye'de bankacılık Sistemi (1958'den itibaren). (2016). Erişim Adresi https://www.tbb.org.tr/tr/bankacilik/banka-ve-sektor-bilgileri/istatistiki-raporlar/59.

TBB, Faaliyet Raporu 2014-2015. (2015). Erişim Adresi https://www.tbb.org.tr/Content/Upload/Dokuman/6258/Faaliyet_Raporu_2014_2015.pdf

Tunay, K. B. (2009). Türk Bankacılık Sektöründe Rekabet ve Kırılganlık. Bankacılar Dergisi, 68, 3055.

Varlık, N. ve Varlık, S. (2016). Risk Algısının Türkiye'de Bankacılık Sektörüne Etkileri: Bankacılık Sağlamlık Endeksi ile Bir Değerlendirme. Yönetim ve Ekonomi: Celal Bayar Üniversitesi iktisadi ve Idari Bilimler Fakültesi Dergisi, 23(2), 545-563.

Yavuz, N.Ç. (2014). Finansal Ekonometri (1. Baskı). İstanbul: Der Kitabevi. 


\section{TURKISH BANKING SECTOR FRAGILITY: AN EMPIRICAL STUDY}

\section{Extended Abstract}

Aim: The banking sector is the most important part of the Turkish financial system. A banking system with a steady structure and an efficient function brings the country economy to a less fragile position against global crises. Developments in the banking sector are of great importance both for the financial sector and for the real sector. Constituting banking fragility index measuring the fragility of the banking sector and then monitoring the BFI and detection of periods of high fragility are important by the economic agents and policy makers. Due to the interaction between the banking sector and the real economy, the developments in the banking sector may affect the economic activity positively or negatively, meanwhile, banking sector will be affected from the changes in the economic conditions. The contraction of economic activity will lead to decrease in the efficiency of the banking sector and cause hitches in fulfillment of the functions which are necessary to regulate the economic system. The aim of this study is to constitue the BFI and examine the relationship between this index and economic activty for the period 2005-2016 of the Turkish economy.

Method(s): In the direction of the the aim of the study, three basic ratios of the banking sector, which are thought to reflect fragility for the Turkish banking sector, were selected to constitue the BFI. These ratios are the non-performing loans, capital adequacy ratio and net profit or loss. In order to define all financial ratios in the same unit, the TA, SC and DNK variables have been standardized. Later, BFI was constituted by weighing financial ratios using the principal component analysis. The positive value of the BFI means that increase the fragility, the negative value of the BFI means that decrease the fragility, and if the BFI takes a zero value means that fragility does not change. The vector autoregressive (VAR) method was used to analyze the dynamic relationship between $\mathrm{BFI}$ and economic activity. Industrial production index growth rate (IPI) was used as a proxy for economic activity. Before the VAR model was estimated, the granger causality test was performed and it was determined whether a causal relationship between the BFI and economic activity in the meaning of granger. The banking sector ratios used in the study were obtained from the Banking Regulation and Supervision Agency's (BRSA) statistic database and the industrial production index obtained from the Central Bank of the Republic of Turkey (CBRT). The data set consists of monthly data covering the 2005-2016 period.

Findings: Firstly, the banking fragility index and industrial production index growth rate were compared and observed to move in opposite directions. It has been observed that the banking fragility index is decreasing (rising) in periods when the industrial production index is rising (decreasing). Afterwards, According to the Granger causality test result, BFI has not significant influence on IPI. However, IPI impacts on BFI. According to the results of the impact response analysis, it was determined that there is a negative relationship between BFI and economic activity and it has been revealed that BFI will rise as a result of contraction in the real economy. Lastly, According to the results of the variance decomposition, the rate of disclosure by the BFI for the prediction error was $90.90 \%$ in the first six months, and decreased in the following six months and was $76.74 \%$ in the 12 th period. It has been determined that the IPI changes are largely selfexplanatory.

Conclusion: in this study, BFI is not a significant influence on economic activity, but it has been found that economic activity is influential on BFI. The results of Granger causality and VAR analysis are consistent with each other and support this finding. Although it has been determined that the developments in the banking sector will not have an impact on the real economy, it can be argued that this is caused by the loss of efficiency resulting from the utilization of the public sector resources more than banking resources, although it is not aimed to increase the efficiency of private sector investments in recent years. 
